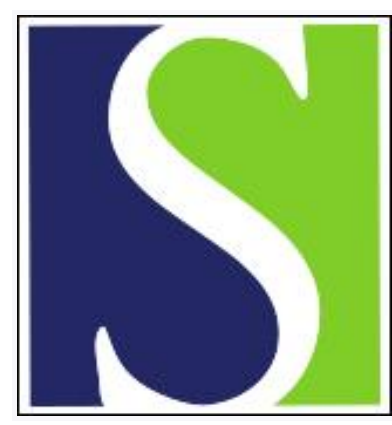

Scand J Work Environ Health 2000;26(6):507-513

https://doi.org/10.5271/sjweh.575

Issue date: Dec 2000

Occupational risk factors for radial tunnel syndrome in industrial workers

by Roquelaure Y, Raimbeau G, Dano C, Martin Y-H, Pelier-Cady M-C, Mechali S, Benetti F, Mariel J, Fanello S, Penneau-Fontbonne D

Key terms: force; MSD; musculoskeletal disorder; nerve entrapment; posture; radial nerve; work-related radial tunnel syndrome; work-related risk factor

This article in PubMed: www.ncbi.nlm.nih.gov/pubmed/11201398

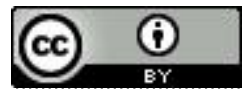




\title{
Occupational risk factors for radial tunnel syndrome in industrial workers
}

\author{
by Yves Roquelaure, MD, Guy Raimbeau, MD, ${ }^{2}$ Corinne Dano, MD, ${ }^{1}$ Yves-Henry Martin, MD, ${ }^{3}$ Marie- \\ Christine Pelier-Cady, MD, ${ }^{2}$ Sophie Mechali, MD, ${ }^{1}$ France Benetti, MD, ${ }^{3}$ Jean Mariel, MD, ${ }^{3}$ Serge Fanello, \\ $M D,{ }^{1}$ Dominique Penneau-Fontbonne, $M D^{1}$
}

\begin{abstract}
Roquelaure Y, Raimbeau G, Dano C, Martin Y-H, Pelier-Cady M-C, Mechali S, Benetti F, Mariel J, Fanello S, Penneau-Fontbonne D. Occupational risk factors for radial tunnel syndrome in industrial workers. Scand J Work Environ Health 2000;26(6):507-513
\end{abstract}

Objectives The aim of the study was to evaluate both nonoccupational and occupational factors associated with radial tunnel syndrome (RTS) among industrial workers in 3 large plants.

Methods Twenty-one cases of RTS were compared with 21 referents matched for gender, age, and plant. RTS was associated with carpal tunnel syndrome (CTS) in 9 cases. Past medical history, household activities, and ergonomic and organizational characteristics of the job were analyzed.

Results The study found 3 occupational risk factors for RTS. Exertion of force of over $1 \mathrm{~kg}$ [odds ratio (OR) 9.1 , 95\% confidence interval (95\% CI) 1.4-56.9] more than 10 times per hour was the main biomechanical risk factor. Prolonged static load applied to the hand during work was strongly associated with RTS (OR 5.9, 95\% CI 1.229.9). Work posture with the elbow fully extended ( $0-45$ degrees) was associated with RTS (OR $4.9,95 \% \mathrm{CI}$ 1.0 -25.0). Full extension of the elbow, associated with a twisted posture of the forearm, stressed the radial nerve at the elbow. However, personal activities, household chores, and sport and leisure activities were not associated with RTS.

Conclusions The study confirms that RTS occurs in workers performing hard manual labor that requires forceful and repetitive movements involving elbow extension and forearm prosupination.

Key terms force, musculoskeletal disorders, nerve entrapment, posture, radial nerve, work-related.

Nerve entrapments represent a large proportion of workrelated upper-limb musculoskeletal disorders (1). The radial tunnel syndrome (RTS) is due to intermittent compression of the radial nerve in the radial tunnel, which extends from the radial head to the inferior border of the supinator muscle, without associated extensor weakness $(2-5)$. The entrapment can be due to a variety of causes, including bands of fascia, the radial recurrent vessels, and the fibrous edge of the origin of the supinator that constitutes the Frohse arcade $(3,6,7)$. Clinically, RTS is manifest as forearm pain without paresis, corresponding to the entrapment of the deep sensory branch of the radial nerve $(3,7)$. The main clinical features of RTS are tenderness over the radial tunnel, 3 to $5 \mathrm{~cm}$ distal to the lateral epicondyle, and painful resisted supination or middle-finger extension. If the entrapment involves the pos- terior interosseous branch, the patient may have pain or weakness at the entrapment site. Appropriately, this condition is known as posterior interosseous nerve entrapment (8).

RTS, which is less often encountered than carpal tunnel syndrome (CTS) and cubital tunnel syndrome (1), has been estimated to be present in $5 \%$ of epicondylitis cases (5). However, little information is available with which to evaluate the prevalence and risk factors of RTS because RTS is often confused with epicondylitis. Observation of industrial workers or heavy manual workers with RTS $(3,7,9,10)$ suggests a cumulative trauma phenomenon and the existence of occupational factors predisposing to RTS. Numerous cases of RTS had been diagnosed among employees of 3 large plants in the area of Angers, where a case-referent study of CTS had

1 Centre de consultation de pathologie professionnelle (Occupational Health Center), Centre Hospitalier Universitaire (University Hospital), Anger, France.

2 Centre de la main (Hand Surgery Center), rue Auguste Gautier, Angers, France.

3 Service Médical Inter-entreprise de l'Anjou (Occupational Health Service of Anjou), Angers, France.

Reprint requests to: Dr Yves Roquelaure, Centre de Consultation de Pathologie Professionnelle, CHU, F-49033 Angers Cedex, France. [E-mail: yvroquelaure@chu-angers.fr] 
previously been conducted (11). A case-referent study of RTS was therefore initiated to examine the respective influences of medical history, nonvocational activities, and work conditions on the causation of RTS in these industrial workers.

\section{Subjects and methods}

The case-referent study was performed in 3 plants where television sets (plant A), shoes (plant B) and automobile brakes (plant $\mathrm{C}$ ) were manufactured. Production-line work was common in these highly efficient manufacturing companies, with 1000,800 and 850 employees, respectively. Subjects with RTS and treated in the same hand surgery center (7) were compared with referents individually matched for gender, age, and plant (A, B, or C).

\section{Subjects}

Cases. Two assessors reviewed all the employees' medical files, completed each year by the same occupational health physician of the company. All blue-collar workers from 18 to 59 years of age with a medical history of RTS, CTS, or other work-related upper-limb musculoskeletal disorders between 1 January 1990 and 30 December 1992 were reviewed. Cases of RTS were preincluded in the study if they had been treated in the same hand surgery center. Then the corresponding medical files of the hand center were reviewed. The cases of RTS were definitively included in the study if the medical files included the following conditions: (i) forearm pain with tenderness along the radial nerve in front of the radial head, 3 to $5 \mathrm{~cm}$ distal to the lateral epicondyle, (ii) positive "middle finger test" (ie, elicitation of pain in the region of the common extensor origin by extension of the middle finger with the elbow extended) or positive "resisted forearm supination test", (iii) positive results of a neurophysiological examination, or (iv) surgical release of the radial nerve, in association with surgical release of the median nerve at the wrist when necessary, between 1 January 1990 and 30 December 1992. The subjects with a long history of RTS or other work-related upper-limb musculoskeletal disorders before 1990 were not included in the study. The few subjects with malignancies, rheumatic disease, thyroid dysfunction, or diabetes before 1 January 1990 were also excluded.

Abnormal electrophysiological findings were required before the surgical release of the radial nerve (7). The same physician performed all the neurophysiological examinations with the same technical setup (Medelec) according to a standardized procedure (7). Room temperature was maintained at $23^{\circ} \mathrm{C}$. The patient was laid on his back with hands pronated. First, electromyography (EMG) was performed on the extensor digitorum communis, the extensor pollici longus, and the extensor indicis muscles with bipolar needles placed at 13,15, and $20 \mathrm{~cm}$ from the elbow crease, respectively. A semiquantitative scale was used to classify the EMG signal (parameter 1). A study of the extensor carpi radialis longus muscle was then performed to eliminate a proximal lesion of the radial nerve. Second, the nerve conduction of the deep branch of the radial nerve was investigated. Motor conduction was evaluated by measuring the distal latency of the nerve (parameter 2) and the motor conduction velocity (MCV) (parameter 3 ). The nerve was therefore stimulated at the level of the lateral part of the elbow crease with detection needles placed in the extensor digitorum communis, extensor polici longus, and extensor indicis at 13,15 , and $20 \mathrm{~cm}$ from the elbow crease, respectively. Distal latency was considered to be abnormal when the value was over $3.5,4.5$, and $5.5 \mathrm{~m} / \mathrm{s}$ for the extensor digitorum communis, extensor polici longus, and extensor indicis, respectively. The MCV was considered normal over $60 \mathrm{~m} / \mathrm{s}$ and abnormal under $50 \mathrm{~m} / \mathrm{s}$. When the MCV was between 50 and $60 \mathrm{~m} / \mathrm{s}$, the interpretation was made by making a comparison with the results of the healthy arm. In doubtful cases, nerve conduction studies were performed with the subject's arms in different positions stressing the radial nerve (resisted supination, resisted wrist extension, wrist flexion of the extended and pronated arm) (parameter 4 ). The results of the neurophysiological study were considered to be abnormal when at least 1 of the 4 parameters was abnormal (7).

In order to study the median nerve, electromyography was performed in the abductor pollicis brevis, flexor pollicis longus, flexor carpi radialis, and also the first dorsal interosseous and brachioradialis muscles to eliminate a lesion of the ulnar or radial nerve. The median nerve was supramaximally stimulated at the elbow to measure the maximal MCV velocity at the forearm and wrist levels. The most symptomatic finger or the $3 \mathrm{rd}$ digit was then stimulated, with a simultaneous recording of the bipolar surface electrodes over the median nerve proximal to the carpal ligament at a distance of $6-8 \mathrm{~cm}$.

The definition of CTS was the presence of at least 3 of the following conditions (11): (i) tingling, pain or numbness, or a combination of the three, in the median nerve distribution of the hand, with nocturnal exacerbation on more than 20 occasions or lasting more than 3 weeks in the previous year, (ii) positive Tinel's sign and positive Phalen's test or hypoesthesia in the territory of the median nerve, or (iii) slowing of sensory or motor conduction velocities $(<40 \mathrm{~m} / \mathrm{s})$ in the median nerve at wrist level or (iv) surgical release of the transverse carpal ligament. The definition of lateral epicondylitis was the presence of (i) pain directly located around the later- 
al epicondyle, (ii) tenderness of the epicondyle, and (iii) local pain on resisted wrist extension.

Altogether 21 workers [ 17 women and 4 men with a mean age of 40.1 (SD 8.0) years] who had been previously diagnosed as having RTS were included in the study. Six worked at plant A, 6 at plant B, and 9 at plant C. RTS was unilateral in 20 cases (12 right, 8 left) and bilateral in 1 case. All the patients had received surgery at the same hand surgery center, and thus all cases of RTS were severe. RTS was simultaneously associated with CTS in 8 cases, with CTS and shoulder tendinitis in 1 case, and with lateral epicondylitis in 2 cases (tables 1 and 2).

Referents. A referent was randomly selected for each case from the blue-collar workers of the same gender, born in the same year, and on the payroll rosters of the corresponding plant. The medical files of all the referents, which were completed each year by the same occupational health physician with the same methodology as the cases, were reviewed by the same 2 assessors. The referents had to be free of symptoms or signs of RTS or

Table 1. Gender, age and clinical findings of the cases of radial tunnel syndrome. (RCS = rotator cuff tendinitis, EPI = epicondylitis).

\begin{tabular}{|c|c|c|c|c|c|c|c|c|c|}
\hline $\begin{array}{l}\text { Case } \\
\text { number }\end{array}$ & Gender & $\begin{array}{l}\text { Age } \\
\text { (years) }\end{array}$ & $\begin{array}{l}\text { Dominant } \\
\text { hand }\end{array}$ & $\begin{array}{l}\text { Affected } \\
\text { elbow }\end{array}$ & EMG & $\begin{array}{l}\text { Surgery for } \\
\text { RTS (year) }\end{array}$ & $\begin{array}{l}\text { CTS } \\
\text { arm }\end{array}$ & $\begin{array}{l}\text { Year of } \\
\text { surgery }\end{array}$ & $\begin{array}{l}\text { Diagnosis of EPI } \\
\text { or RCS (year) }\end{array}$ \\
\hline 1 & Female & 39 & Right & Left & + & 1992 & . & . & $\cdot$ \\
\hline 2 & Male & 31 & Right & Right & + & 1992 & . & . & . \\
\hline 3 & Female & 47 & Right & Left & + & 1990 & . & . & . \\
\hline 4 & Female & 42 & Right & Left & + & 1990 & . & . & . \\
\hline 5 & Female & 30 & Right & Right & + & 1992 & . & & . \\
\hline 6 & Male & 44 & Right & Left & + & 1992 & . & . & . \\
\hline 7 & Male & 38 & Right & Right & + & 1992 & . & . & . \\
\hline 8 & Female & 52 & Right & Right & + & 1991 & . & . & . \\
\hline 9 & Female & 37 & Right & Left & + & 1992 & . & . & $\cdot$ \\
\hline 10 & Female & 28 & Right & Right & + & 1991 & . & . & . \\
\hline 11 & Female & 36 & Right & Right & + & 1991 & . & . & 1992 (EPI, right) \\
\hline 12 & Female & 37 & Right & Left & + & 1991 & . & . & 1991(EPI, right) \\
\hline $13^{2}$ & Male & 36 & Right & Right & + & 1992 & Right & 1992 & \\
\hline $14^{\mathrm{a}}$ & Female & 56 & Right & Right & + & 1992 & Right & 1992 & \\
\hline $15^{a}$ & Female & 49 & Right & Right & + & 1990 & Both & 1992 & . \\
\hline $16^{a}$ & Female & 48 & Right & Right & + & 1991 & Right & 1991 & . \\
\hline $17^{\mathrm{a}}$ & Female & 35 & Right & Left & + & 1990 & Left & 1991 & 1992 (RCS, left) \\
\hline $18^{a}$ & Female & 36 & Right & Both & + & 1991 & Both & 1991 & \\
\hline $18^{a}$ & Female & 38 & Left & Left & + & 1991 & Left & 1991 & . \\
\hline $20^{a}$ & Female & 45 & Right & Right & + & 1990 & Right & 1990 & . \\
\hline $21^{a}$ & Female & 37 & Right & Right & + & 1990 & Right & 1990 & \\
\hline
\end{tabular}

a Cases of RTS associated with CTS.

Table 2. Characteristics of the workstations of the cases. (Plant $A=$ televison assembly, plant $B=$ shoe assembly and sewing, $C=$ brake assembly).

\begin{tabular}{|c|c|c|c|c|c|c|}
\hline $\begin{array}{l}\text { Case } \\
\text { number }\end{array}$ & Plant & $\begin{array}{l}\text { Employment } \\
\text { in company } \\
\text { (years) }\end{array}$ & $\begin{array}{l}\text { Employment } \\
\text { at workstation } \\
\text { (years) }\end{array}$ & Workstation & $\begin{array}{l}\text { Force } \\
(\mathrm{kg})\end{array}$ & $\begin{array}{l}\text { Cycle time } \\
\text { (second) }\end{array}$ \\
\hline 1 & B & 19 & 10 & Assembling & $<1$ & 20 \\
\hline 2 & $\mathrm{~B}$ & 12 & 10 & Smelting & $<1$ & 20 \\
\hline 3 & $B$ & 13 & 12 & Sewing & $<1$ & 20 \\
\hline 4 & $\mathrm{~B}$ & 19 & 18 & Sewing & $<1$ & 20 \\
\hline 5 & $B$ & 13 & 13 & Sewing & $<1$ & 20 \\
\hline 6 & C & 19 & 13 & Assembling & 2 & 20 \\
\hline 7 & $\mathrm{C}$ & 22 & 22 & Assembling & $<1$ & 20 \\
\hline 8 & C & 17 & 10 & Machining & 2 & 20 \\
\hline 9 & $\mathrm{C}$ & 16 & 16 & Computer & $<\overline{1}$ & 45 \\
\hline 10 & $\mathrm{C}$ & 10 & 2 & Assembling & 2 & 20 \\
\hline 11 & $\mathrm{C}$ & 18 & 2 & Assembling & 2 & 20 \\
\hline 12 & $\mathrm{C}$ & 19 & 11 & Assembling & $<1$ & 20 \\
\hline $13^{a}$ & $A$ & 3 & 2 & Assembling & 3 & 36 \\
\hline $14^{a}$ & A & 30 & 1 & Assembling & $<1$ & 20 \\
\hline $15^{a}$ & A & 19 & 2 & Assembling & 3 & 20 \\
\hline $16^{\mathrm{a}}$ & $A$ & 29 & 1 & Assembling & $<1$ & 20 \\
\hline $17^{a}$ & A & 16 & 5 & Machine tuning & 3 & 36 \\
\hline $18^{a}$ & A & 16 & 1 & Assembling & $<1$ & 36 \\
\hline $18^{a}$ & B & 22 & 9 & checking shoes & $<1$ & 20 \\
\hline $20^{\mathrm{a}}$ & $\mathrm{C}$ & 19 & 1 & Assembling & 2 & 20 \\
\hline $21^{a}$ & C & 17 & 15 & Assembling & 2 & 20 \\
\hline
\end{tabular}

a Cases of RTS associated with CTS. 
work-related musculoskeletal disorders of the upper limbs from 1984 to 1992 . No nerve conduction studies were performed. The exclusion criteria were the same as those applied to the cases. Twenty-one referents [17 women and 4 men with a mean age of 40.4 (SD 7.1) years] were included in the study.

\section{Data collection}

Medical history. The medical files of all the cases and referents were reviewed. Past medical history before the onset of RTS, or the corresponding date for the matched referent, was studied. Information on weight, height, hand dominance, smoking habits, and alcohol consumption, which was systematically included in the medical records, was also studied, as was the use of analgesics, steroids and nonsteroid anti-inflammatory drugs. Information about pregnancy, natural menopause, gynecological surgery, and oral contraceptives was also collected.

Nonoccupational activities were assessed by the use of a self-administered questionnaire. Information was collected on educational level, marital situation, household chores such as cleaning, sewing, knitting, odd jobs and gardening, and the playing of musical instruments and physical exercise.

Occupational activities. The workstation studied was the one occupied by the cases 6 months before the diagnosis of RTS. For the referents, it was the workstation occupied at the end of 1992. The length of employment and the duration of previous manual work were calculated at the date of diagnosis of RTS for the cases and at the corresponding date for the matched referents. Previous work was considered repetitive if the cycle time was under 30 seconds, and with high force if it required prehensile efforts of $>1 \mathrm{~kg}$ more than 10 times per hour.

A job-site work analysis was performed in 1993 by direct observation by 2 specially trained assessors unaware of the medical status of the persons and by the use of the same checklist for the cases and referents. When workers had 2 or more workstations, the analysis was performed on the workstation most often occupied. Job rotation of workers between different workstations was recorded. Workstation information included the way in which parts were supplied to and forwarded from the workstation, as well as the number of parts produced. Also taken into account were the types of tools used, the nature of the materials, and the work cadence. Exposure to cold and vibration was recorded. Motion repetitiveness and segmental postures of the upper limb were evaluated for the task carried out most often during the day. A step-by-step description of the motions required to perform the job was carried out according to the motion time methods modified by Armstrong et al (12). The number of motions per cycle time and the length of the shortest elementary operation were calculated as the average of
10 work cycles. Workhours and breaks were measured. A checklist based on the RULA method (13) was used to evaluate the angular position of the elbow [full extension ( $0-45$ degrees), mild flexion (45-90 degrees), complete flexion ( $>90$ degrees)], forearm [neutral, pronation-supination ( $>30$ degrees)], and wrist [flexion ( $>45$ degrees), neutral, extension ( $>45$ degrees)]. The frequency of certain activities (pinching, gripping, driving screws, pulling, pushing, lifting, turning), the nature of the motion performed by the hand (precise, forceful), and static loading of the hand were assessed by direct observation. Static work of the hand refers to isometric contractions of the hand (ie, muscular effort with no finger movement). Static work occurring during the majority of the cycle time was considered significant. Hand-exerted forces were determined by the weight of the tools and the parts handled. Force was considered "high" when the load was $>1 \mathrm{~kg}$, with a frequency of exertion over 10 per hour.

\section{Statistical methods}

The cases and referents were individually matched for age and gender. Matched odds ratios were calculated; the McNemar test was used to estimate the association between RTS and dichotomous exposure factors. Quantitative data were analyzed by paired Wilcoxon 1-sample tests. Only univariate associations between RTS and dichotomous factors with a P-value below 0.20 were taken into consideration in the multivariate analysis. Conditional backward logistic regression analysis was used to estimate associations between RTS and exposure factors. Cases with associated CTS were compared with those without CTS, with the use of Student tests and proportion comparison tests. Data acquisition was performed using the SPSS 10.0 computer program (SPSS Inc, Chicago, Illinois, United States).

\section{Results}

Medical history. Body mass index (BMI) did not differ significantly between the cases and referents [24.9 (SD 4.9) versus $24.8(\mathrm{SD} 3.0) \mathrm{kg} / \mathrm{m}^{2}, \mathrm{P}=0.98$ ]. Obesity (BMI $>30$ ) was not associated with RTS (14\% versus $5 \%$, $\mathrm{P}=0.30$ ). The number of current smokers was not significantly higher in the case group ( $\mathrm{P}=0.66)$. No association was found between RTS and hysterectomy $(\mathrm{P}=1.00)$, ovariectomy ( $\mathrm{P}=0.60)$, menopause $(\mathrm{P}=0.60)$, or the use of oral contraceptives $(\mathrm{P}=0.53)$. The parity in the case group [1.7 (SD 1.5)] was similar to that in the reference group $[1.9(\mathrm{SD} 1.5)](\mathrm{P}=0.53)$.

Nonoccupational activities. The average weekly duration of household chores was similar in both groups [7.7 (SD 
6.1) versus 7.9 (SD 2.9) hours, $P=0.90]$. Over 1 hour of household chores per day was not associated with RTS ( $95 \%$ versus $85 \%, \mathrm{P}=0.30$ ). There was no difference concerning do-it-yourself activities $(\mathrm{P}=0.70)$, gardening $(\mathrm{P}=0.72)$, playing of musical instruments $(\mathrm{P}=0.80)$, and sports $(\mathrm{P}=0.69)$.

Occupational exposure. The length of service in the company was similar in both groups [16.9 (SD 6.6) versus 14.5 (SD 8.7) years, $\mathrm{P}=0.69$ ]. Duration of exposure to repetitive work did not significantly differ between the groups $(\mathrm{P}=0.36)$. The average years at the same workstation were high for both groups [8.3 (SD 6.5) versus 10.4 (SD 6.6) years, $P=0.314]$. Daily worktime was similar for both groups (ie, 7.5 hours). In addition, there was no difference in the average number of breaks and the total average length of breaks during the day.

The univariate analysis gave the following results. RTS was not associated with the absence of job rotation ( $62 \%$ versus $71 \%, \mathrm{P}=0.17$ ) nor with the manual recharging of workstation supplies ( $42 \%$ versus $29 \%, \mathrm{P}=0.24$ ). A cycle time of $<30$ seconds was more frequent in the case group ( $81 \%$ versus $62 \%, P=0.049$ ). The number of elementary actions was more frequently less than 5 in the case group ( $33 \%$ versus $5 \%, \mathrm{P}=0.004$ ). A short duration ( $<10$ seconds) of the shortest elementary action was associated with RTS (95\% versus $76 \%, \mathrm{P}<0.001$ ). Force of $>1 \mathrm{~kg}$ was more frequent in the case group ( $43 \%$ versus $10 \%, \mathrm{P}=0.013)$. Full extension of the elbow during work was more frequent in the case group (76\% versus $48 \%, \mathrm{P}=0.057$ ) as was holding the forearm in an extreme twisted position (pronation or supination) (28\% versus $12 \%, \mathrm{P}=0.049$ ). Static work of the hand was also more frequent in the case group ( $48 \%$ versus $24 \%, \mathrm{P}=0.10$ ). No association was found with wrist flexion $(\mathrm{P}=0.33)$ or with wrist extension $(\mathrm{P}=0.38)$. RTS was not associated with pinching ( $\mathrm{P}=0.75)$, gripping $(\mathrm{P}=0.48)$, and pulling $(\mathrm{P}=0.33)$. Precision work was more frequent in the case group ( $48 \%$ versus $19 \%, \mathrm{P}=0.12$ ).

The logistic analysis revealed 3 work-related risk factors (table 3 ). Exertion of effort of $>1 \mathrm{~kg}$ more than 10 times per hour was strongly associated with RTS (OR 9.1, 95\% CI 1.4-56.9). No variable describing repetition rate was associated with RTS. Static work of the hand, such as firmly pinching or squeezing objects or handtools, was strongly associated with RTS (OR 5.9, $95 \%$ CI 1.2-29.9). Working with the elbow fully extended regularly was also associated with RTS (OR 4.9, 95\% CI 1.0-25.0). The OR between RTS and holding the forearm in an extreme and twisted position was high but did not reach statistical significance (OR4.4, 95\% CI $0.7-20.7$ ). This model did not reveal any other posture of the wrist or any other specific motion of the hand in association with RTS. No personal factors or nonoccupational tasks were associated with RTS.

The cases were categorized according to the presence, or absence, of associated CTS. Age [42.2 (SD 7.5) versus 38.4 (SD 7.1) years, $\mathrm{P}=0.24]$ and $\mathrm{BMI}(\mathrm{P}=0.38)$ did not significantly differ between the groups. Past medical history and nonoccupational activities were similar for both groups. Years of service at the same workstation were lower when RTS was associated with CTS [4.1 (SD 4.9 ) versus 11.5 (SD 5.9) years, $P=0.007]$. No differences were observed for job characteristics such as cycle time, number or duration of elementary operations, force level, or static work of the hand between the groups. However, full extension of the elbow during work was less frequent when RTS was associated with CTS (55\% versus $92 \%, \mathrm{P}=0.06$ ).

\section{Discussion}

As in the majority of previous studies $(3,4,7,9,10,14)$, few cases of RTS were included in this study because of the low prevalence of the disorder. The inclusion criteria were very strict in order to avoid misclassification between RTS and epicondylitis. All the cases of RTS had been treated surgically at the same hand center, which provides anatomic assessment of nerve entrapment. EMG and nerve conduction studies ruled out other sites of radial nerve entrapment $(7,8,15)$. Although

Table 3. Risk factors for radial tunnel syndrome in the logistic model. ${ }^{a}$ ( $O R=$ odds ratio, $95 \% \mathrm{Cl}=95 \%$ confidence interval)

\begin{tabular}{|c|c|c|c|c|c|c|}
\hline \multirow[b]{2}{*}{ Risk factor ${ }^{b}$} & \multicolumn{2}{|c|}{ Cases } & \multicolumn{2}{|c|}{ Referents } & \multirow[t]{2}{*}{$\mathrm{OR}$} & \multirow[t]{2}{*}{$95 \% \mathrm{Cl}$} \\
\hline & $N$ & $\%$ & $\mathrm{~N}$ & $\%$ & & \\
\hline $\begin{array}{l}\text { Force }>1 \mathrm{~kg} \text { than } 10 \text { times/hour } \\
\text { Static work of the hand occurring during the majority of the cycle time } \\
\text { Full extension of the elbow ( } 0-45 \text { degrees) during work }\end{array}$ & $\begin{array}{c}9 \\
10 \\
8\end{array}$ & $\begin{array}{l}43 \\
48 \\
38\end{array}$ & $\begin{array}{l}2 \\
5 \\
4\end{array}$ & $\begin{array}{l}10 \\
24 \\
19\end{array}$ & $\begin{array}{l}9.0 \\
5.9 \\
4.9\end{array}$ & $\begin{array}{l}1.4-56.9 \\
1.2-29.9 \\
1.0-25.0\end{array}$ \\
\hline
\end{tabular}

Likelihood ratio test $=43.558$; goodness of fit $=45.234$, degree of freedom $=3$

a The following variables were tested in the model: exertion of force of $>1 \mathrm{~kg}$ more than 10 times/hour, cycle time $<30$ seconds, number of motions per cycle time $<4$, duration of the shortest elementary operation $\geq 10$ seconds, static work of the hand occurring during the majority of the cycle time, forearm prosupination over 30 degrees, full extension $(0-45$ degrees) of the elbow, tasks involving precise hand motions during the majority of the cycle time, absence of job rotation of workers between different workstations.

- Dichotomous factors. The reference is the alternative. 
neurophysiological assessment of the deep branch of the radial nerve is difficult $(4,14)$, the requirement of abnormal neurophysiological studies did not exclude many potential cases because most patients undergoing radial nerve release had positive electrophysiological findings before the operation (7). This situation can be explained by the technique used. First, the neurophysiological studies were considered to be positive when at least 1 of the 4 parameters was positive. When all the criteria were negative, the study was repeated 6 months later (7). Second, the use of differential latency testing with the arm in different stress postures is a more sensitive test for RTS than conventional nerve conduction studies (15). Although the referents did not undergo electrophysiological studies, the classification bias between the cases and referents was probably low because the occupational health physician filled out the medical files in an identical manner.

Although the cases of RTS included in the study were severe, the vast majority of the patients had resumed work at the same workstation after surgery. This solution was not due only to the success of the surgery but also due to the fact that it was impossible to offer the patients less stressful jobs in their companies. Because of the high number of years of service at the same workstation, exposure assessment bias was probably low and identical for both groups.

The produced RTS model was a multifactorial model with 3 occupational factors. The main biomechanical risk factor was the high level of prehension forces. The hand load threshold chosen as high was $1 \mathrm{~kg}$ because very few workers exerted efforts in excess of 4 or even $2 \mathrm{~kg}$. Although the definition of high force did not refer to the duration of force exertion during the cycle time, the frequency of force exertion could be estimated as at least 4 per minute. A 1-kg effort can be considered significant because the workers most often exercised precise motions and pinching rather than full-hand grasping (16). The increased risk of RTS when the force level was high is in agreement with that of previous studies reporting RTS in workers engaged in hard manual labor $(5,9,11,17)$. Static work of the hand occurred during activities such as holding a handtool or pinching a piece of leather or an electronic component. The duration of exposure to static work of the hand was often less than 1 minute, which is the threshold proposed by the RULA method, because of the short duration of the cycle time at almost all of the workstations. The association between static work of the hand and RTS is in agreement with the ergonomic literature on work-related upper-limb musculoskeletal disorders (1).

A work posture with the arm extended was clearly identified as a risk factor, particularly when it is associated with extreme twisting of the forearm. This result is in agreement with those of clinical studies showing the occurrence of RTS in manual workers performing repetitive tasks and forceful forearm prosupination and elbow flexion or extension $(3,7,9,10)$. The result also corroborates the findings of anatomic studies showing the dynamic conflict between the radial nerve and the entrapment site when the elbow is extended with the forearm in full supination $(5,9)$. The deep branch of the radial nerve undergoes wave movements ahead of the radiohumeral joint during twisting of the forearm, while the nerve is axially stressed by flexion or extension of the elbow (7). The supinator muscle plays a major role in the intermittent compression of the nerve since the space between the 2 chiefs of the muscle constitutes a furrow. The space available for the radial nerve varies with movements of prosupination of the forearm at the site of entrapment $(5,7)$. Thus the pressure applied on the nerve varies with the posture of the upper limb and the force exerted by the hand (18).

No association was found between RTS and the repetitiveness of the task, expressed as cycle time or motion diversity, because all the workers experienced short time cycles and high work repetitiveness. Unlike the situation with CTS, a lack of job rotation and other work organization characteristics were not identified as risk factors for RTS (11). This difference was probably due to the lack of statistical power of the study. Toomingas et al (19) reported an association between a high risk of local tenderness over the radial tunnel and self-reported low social support and high job strain. Psychosocial factors may have played a role in our study, but they were nevertheless not taken into consideration because of the retrospective nature of the assessment of the exposure.

In agreement with the findings of previous studies, RTS was often associated with CTS (4) or epicondylitis $(5,9)$. These cases were not excluded, however, in order to increase the statistical power of the case-referent study. Few differences were observed between the cases of RTS with and without CTS.

Lower years of service at the workstation of the cases of RTS associated with CTS could be explained by longer periods of sick leave. Such patients had frequently undergone $\geq 2$ surgical releases of nerve entrapment. Exposure to occupational risk factors was similar for both groups, except for full extension of the elbow. Since full extension of the elbow is less frequent for RTS with CTS than for RTS without CTS, the strength of association between RTS and this posture could have been underestimated by the study. According to the results of a previous case-referent study of CTS using the same methodology in the same plants (11), the risk factors of RTS differ from those of CTS. We can therefore assume that the inclusion of cases with CTS probably did not obscure the pattern of determinants for RTS.

In summary, RTS is probably an underestimated cause of work-related upper-limb musculoskeletal disor- 
ders. Hard manual work, particularly forceful and repetitive forearm prosupination with the elbow extended, is the leading cause of RTS. Prevention of this disorder should therefore be furthered by reducing efforts and postures with the elbow extended and twisted, and such a reduction requires technical and organizational solutions.

\section{Acknowledgments}

The authors are grateful to the French Ministry of Research and Technology for funding (grant 92-D-094) and to Mrs A Leclerc (National Institute of Health and Medical Research, unit 88) for her valuable comments on the manuscript.

\section{References}

1. Hagberg M, Silverstein B, Wells R, Smith R, Hendrick HW, Carayon $\mathrm{P}$, et al, editors. Work related musculoskeletal disorders (WMSDs): a reference book for prevention. London: Taylor \& Francis, 1995.

2. Capener N. The vulnerability of the posterior interosseous nerve of the forearm: a case report and an anatomical study. $J$ Bone Joint Surg 1966;48B:770-83.

3. Roles NC, Maudsley R. Radial tunnel syndrome: resistant tennis elbow as nerve entrapment. J Bone Joint Surg 1972;54B:499-508.

4. Ritts JD, Wood MB, Linscheid RL. Radial nerve syndrome - a ten-year surgical experience. Clin Orthop 1987; 219:201-5.

5. Werner CO. Lateral elbow pain and posterior interosseous nerve entrapment. Acta Orthop Scand 1979;supp1 174:1—62.

6. Lister GD, Belsoe RB, Kleinert HE. The radial tunnel syndrome. J Hand Surg 1979;4:52-9.

7. Raimbeau G, Saint-Cast Y, Pelier-Cady MC. Radial Tunnel syndrome: study of a continuous and homogenous series of 35 cases. Rev Chir Orthop 1990;76:177-84.
8. Simmons BP, Wyman ET. Occupational injuries of the elbow. In: Millender LH, Louis DS, Simmons BP, editors. Occupational disorders of the upper extremity. New York: Churchill Livingstone, 1992:155-76.

9. Hagert CG, Lundborg G, Hansen T. Entrapment of the posterior interosseous nerve. Scand J Plast Reconstr Surg 1977;11:205-12.

10. Atroshi I, Johnsson R, Ornstein E. Radial tunnel release: unpredictable outcome in 37 consecutive cases with a $1-5$ years follow-up. Acta Orthop Scand 1995;66:255-7.

11. Roquelaure Y, Mechali S, Dano C, Fanello S, Benetti F, Bureau D, et al. Occupational and personal risk factors for carpal tunnel syndrome in industrial workers. Scand J Work Environ Health 1997;23:364-9.

12. Armstrong TJ, Radwin RG, Hansen DJ, Kemnedy KW. Repetitive trauma disorders: job evaluation and design. Hum Factors 1986;28:325-36.

13. McAtamney L, Corlett EL. RULA: a survey method for the investigation of work-related upper limb disorders. Appl Ergon 1993;24:91-9

14. Lawrence T, Mobbs P, Fortem Y, Stanley JK. Radial tunnel syndrome: a retrospective review of 30 decompressions of the radial nerve. J Hand Surg 1995;20B:454 -9.

15. Kupfer DM, Bronson J, Lee GW, Beck J, Gillet J. Differential latency testing: a more sensitive test for radial tunnel syndrome. J Hand Surg 1998;23A:859—64

16. Stetson DS, Keyserling WM, Silverstein BA, Armstrong TJ, Leonard JA. Observational analysis of the hand and wrist: a pilot study. Appl Occup Environ Hyg 1991;6:927-37.

17. Jebson PJL, Engber WD. Radial tunnel syndrome: 1ong-term results of surgical decompression. J Hand Surg 1997; 22A:889-96.

18. Werner CO, Haeffner F, Rosen I. Direct recording of local pressure in the radial tunnel during passive stretch and active contraction of the supinator muscle. Arch Orthop Trauma Surg 1980;96:291-301.

19. Toomingas A, Theorell T, Michelsen H, Nordemar R, Stockholm MUSIC I Study group. Associations between self-rated psychosocial work conditions and musculoskeletal symptoms and signs. Scand J Work Environ Health 1997;23:130—9.

Received for publication: 23 February 2000 